\title{
Construction of Chimeric Insecticidal Proteins between the 130-kDa and 135-kDa Proteins of Bacillus thuringiensis subsp. aizawai for Analysis of Structure-Function Relationship
}

\author{
Keiko Nakamura, Kazuyuki Oshie, Masatoshi Shimizu, \\ Yoji TaKada, * Kenji OEda \\ and Hideo OHKAWA \\ Biotechnology Laboratory, and * Agricultural Science Research Laboratory, \\ Takarazuka Research Center, Sumitomo Chemical Co., Ltd., \\ Takatsukasa 4-2-1, Takarazuka, Hyogo 665, Japan \\ Received September 20, 1989
}

\begin{abstract}
Eight chimeric insecticidal protein (IP) genes were constructed between the 130-kDa and 135-kDa IP genes of Bacillus thuringiensis subsp. aizawai, and expressed in Escherichia coli JM103 cells. The characterization of the produced chimeric IPs indicated that the variable region (VR1) in the aminoterminal half of the IPs is responsible for the insecticidal activity against larvae of Spodoptera litura and Plutella xylostella. The carboxy-terminal half of VR1 was important for the formation of the 60$\mathrm{KDa}$ active fragment in the gut juice of $S$. litura larvae. Also, combination of the other two variable regions (VR2 and VR3), which were in the central and carboxy-terminal portions of the IPs, appeared to be related to the solubility of the IPs in the gut juice.
\end{abstract}

Bacillus thuringiensis strains produce proteinaceous crystals which are toxic to insect larvae such as Lepidoptera, Diptera, and Coleoptera. ") Protein crystals of each strain contain more than one insecticidal protein (IP) with molecular masses ranging from $28 \mathrm{kDa}$ to $140 \mathrm{kDa}$. In particular, lepidopteran toxin crystals, which consists of $130-\mathrm{kDa}$ to $135-$ $\mathrm{kDa}$ IPs, are dissolved in an alkaline gut juice and are processed by gut-juice proteases to yield active fragments with molecular masses of approximately $60 \mathrm{kDa}$ upon ingestion by susceptible insect larvae. ${ }^{2)}$ A number of lepidopteran toxin genes were cloned from several serotypes of $B$. thuringiensis and some of them were expressed in Escherichia colt ${ }^{3-11)}$ and $B$. subtilis. ${ }^{12.13)}$

We cloned both $130-\mathrm{kDa}$ and $135-\mathrm{kDa}$ IP genes from $B$. thuringiensis subsp. aizawai IPL7, which is insecticidal against lepidopteran larvae. ${ }^{14.15}$ Comparison of the primary structures deduced from the $130-\mathrm{kDa}$ and 135 $\mathrm{kDa}$ IP genes showed that the IPs have $90.2 \%$ similarity in their total sequences and amino acid differences occur mainly in three variable regions. Also, both $130-\mathrm{kDa}$ and $135-\mathrm{kDa}$ IP genes were expressed in E. coli cells. The 130$\mathrm{kDa}$ IP produced had much higher insecticidal activities against Plutella xylostella and Spodoptera litura than the $135-\mathrm{kDa}$ IP.

In this report, we constructed expression plasmids for eight chimeric IPs by exchanging fragments prepared by the cleavage at homologous sites of both $130-\mathrm{kDa}$ and the $135-\mathrm{kDa}$ IP genes, and expressed them in $E$. coli cells to produce chimeric IPs. The chimeric IPs produced were examined for solubility in an alkaline buffer, proteolytic processing by gut-juice proteases, and insecticidal activity against larvae of S. litura and $P$. xylostella. The structure-function relationship of the 130 $\mathrm{kDa}$ and 135-kDa IPs was also discussed.

\section{Materials and Methods}

Biochemicals. Restriction enzymes, DNA modifying enzymes, and a DNA ligation kit were purchased from Takara Shuzo Co., Ltd. (Kyoto, Japan).

Bacterial strains, plasmids and media. Escherichia coli strains JM109 [recAl endAI gyrA96 thi hsdR17 supE44 
rel $A 1 \lambda^{-} \Delta($ lac-pro $A B), F^{\prime}$ traD36 pro $A B$ lacI $\left.Z \Delta M 15\right]$ and JM103 thi strA supE endA sbcB15 hsdR4 A(lac-pro), F'traD36 proAB lacI $Z \Delta M 15]$ were obtained from Pharmacia Biochemicals Co., Ltd. (Uppsala, Sweden). The vector $\mathrm{pKK} 223-4$, and the expression plasmids $\mathrm{pTB} 1$ for the $130-\mathrm{kDa}$ IP gene and $\mathrm{pKC} 6$ for the $135-\mathrm{kDa}$ IP gene were described previously. ${ }^{14,15)} E$. coli cells carrying each of the constructed plasmids were cultivated at $37^{\circ} \mathrm{C}$ in L-broth supplemented with $100 \mu \mathrm{g} / \mathrm{ml}$ of ampicillin.

Recombinant DNA procedure. Plasmid DNAs were prepared from $E$. coli cells by the method of Birnboim and Doly. ${ }^{16)}$ Restriction DNA fragments were recovered from corresponding agarose gel slices after $0.8 \%$ agarose gel electrophoresis. Transformation of $E$. coli cells was done as described by Cohen et al. ${ }^{17}$

Construction of expression plasmids for chimeric IPS. The expression plasmid pTB1 for the $130-\mathrm{kDa}$ IP gene was digested with Kpn I and Pst I to obtain a Kpn I-Pst I fragment $(6.7 \mathrm{~kb})$ which was called fragment $\mathrm{Al}$. The plasmid pTBI was also digested with Kpn I, HindIII, and $P s t \mathrm{I}$ to isolate $K p n \mathrm{I}-H i n d I I I(0.6 \mathrm{~kb})$ and $H i n \mathrm{dIII}-P_{s t \mathrm{I}}$ $(0.7 \mathrm{~kb})$ fragments, called fragments $\mathrm{A} 2$ and $\mathrm{A} 3$, respectively. Similarly, Kpn I-Pst I $(6.7 \mathrm{~kb}), \quad K p n \mathrm{I}-H$ Hin dIII $(0.7 \mathrm{~kb})$, and Hin dII-Pst I $(0.7 \mathrm{~kb})$ fragments, called fragments $\mathrm{C} 1, \mathrm{C} 2$, and $\mathrm{C} 3$, respectively, were prepared from the expression plasmid pKC6 for the $135-\mathrm{kDa}$ IP gene. The resulting DNA fragments $\mathrm{A} 1$ (C1), A2 (C2), and A3 (C3) were religated with a change in assortment and then introduced into $E$. coli $\mathrm{JM} 109$ cells to construct six expression plasmids, pACC1, pCAA1, pAAC1, pCACl, pACA1, and pCCA1. The expression plasmids pACA1 and pCCAI were digested by Bam $\mathrm{HI}$ and then partially digested by Eco RI to isolate Bam HI-Eco RI $(1.1 \mathrm{~kb})$ fragments, called fragments $\mathrm{All}$ and $\mathrm{Cl}$, respectively. The plasmids pACAI and pCCAl were also digested with $E c o$ RI and Eco RV to prepare Eco RI-Eco RV $(0.6 \mathrm{~kb})$ fragments, called fragments $\mathrm{A} 12$ and $\mathrm{C} 12$. Similarly, a Eco RV-Bam HI fragment $(6.4 \mathrm{~kb})$ called fragment CA was prepared from pCCA1. Those DNA fragments were ligated in combinations of $\mathrm{Al} 1, \mathrm{Cl} 2$, and $\mathrm{CA}$, or $\mathrm{Cl1}$, $\mathrm{A} 12$, and $\mathrm{CA}$ to construct two expression plasmids, pACCA1 and pCACA3, respectively. The structures of these plasmids were confirmed by restriction enzyme mapping.

Protein analysis. E. coli cells harboring each of the expression plasmids were grown at $37^{\circ} \mathrm{C}$ in L-broth to a density of $2 \times 10^{8}$ cells $/ \mathrm{ml}$. The cells were harvested from $40-\mu \mathrm{l}$ samples of the cultures and suspended in $30 \mu \mathrm{l}$ of a sample buffer [ $2 \%$ sodium dodecyl sulfate (SDS), $10 \%$ glycerol, $5 \% 2$-mercaptoethanol, and $62.5 \mathrm{~mm}$ Tris hydrochloride ( $\mathrm{pH} \mathrm{6.8)}$ ), and boiled for $5 \mathrm{~min}$, cooled, and sedimented at $12,000 \times g$ for $10 \mathrm{~min}$. The clear supernatants obtained were analyzed by $\operatorname{SDS}-7.5 \%$ polyacrylamide gel electrophoresis (PAGE). ${ }^{18}$ ) Proteins were stained with Coomassie brilliant blue.

Isolation of inclusion bodies from recombinant $E$. coli cells. Transformed E. coli cells (I g wet weight) were harvested from cultures at stationary phase, resuspended in $20 \mathrm{ml}$ of distilled water, and disrupted by sonication $(10 \mathrm{~min}, 40 \mathrm{~W})$ with a Branson Sonifier 250 after twice freeze-thaw treatments. Inclusion bodies were collected by centrifugation of the resulting cell extracts at $6,000 \times g$ for $5 \mathrm{~min}$.

Solubilization of inclusion bodies in an alkaline buffer. Isolated inclusion bodies ( $34 \mu \mathrm{g}$ protein) were suspended in $36 \mu \mathrm{l}$ of $25 \mathrm{mM} \mathrm{Na} \mathrm{CO}_{3}-\mathrm{HCl}$ buffer ( $\mathrm{pH} 9.65$ ), and incubated at $30^{\circ} \mathrm{C}$ for $60 \mathrm{~min}$. The suspensions were centrifuged at $10,000 \times g$ for $10 \mathrm{~min}$ to separate supernatant fractions (soluble fractions) from pellets (insoluble fractions). Samples of both soluble and insoluble fractions were analyzed by SDS- $10 \%$ PAGE.

Digestion of chimeric IPs in a larval gut juice of Spodoptera litura. Fourth-instar larvae of $S$. litura were nipped with a forceps and vomited matters were centrifuged at $10,000 \times g$ for $10 \mathrm{~min}$ to collect a gut-juice fraction. Inclusion bodies $(17 \mu \mathrm{g}$ protein) were suspended in $18 \mu 1$ of $25 \mathrm{~mm} \mathrm{Na} \mathrm{CO}_{3}-\mathrm{HCl}$ buffer (pH 9.65) and incubated at $30^{\circ} \mathrm{C}$ with $2 \mu$ of the gut-juice fraction, which was diluted five-fold with the carbonate buffer. The boiled sample buffer $(20 \mu 1)$ was added to each of the reaction mixtures to stop digestion, and then half of the volume of each reaction mixture was analyzed by SDS-10\% PAGE. Purification of a $60-\mathrm{kDa}$ fragment from a digestion mixture of the $130-\mathrm{kDa}$ IP was done as described by Nagamatsu et al. ${ }^{\text {(9) }}$

Insecticidal activity. Chimeric IPs prepared from recombinant $E$. coli cells were assayed for insecticidal activity against larvae of $S$. litura and $P$. xylostella. For tests against $S$. litura, $1 \mathrm{ml}$ of a suspension of each of the chimeric IPs ( $1 \mathrm{mg}$ or $0.3 \mathrm{mg}$ protein per $\mathrm{ml}$ of distilled water) was added to $13 \mathrm{~g}$ of an artificial diet, which was then fed to ten of the fourth-instar larvae at $25^{\circ} \mathrm{C}$. Mortality was monitored after 3 days. For tests against $P$. $x y l o s t e l l a$, a punched cabbage leaf with a diameter of $5 \mathrm{~cm}$ was dipped into a protein suspension of chimeric IPs ( 2 or $0.2 \mu \mathrm{g}$ protein per $\mathrm{ml}$ of distilled water), and then dried at room temperature. Ten of the third-instar larvae were fed on the leaf disk at $25^{\circ} \mathrm{C}$, and mortality was monitored after 4 days.

\section{Results}

Construction of expression plasmids for chimeric IPS

Figure 1 illustrates the overall strategy for construction of expression plasmids for chimer- 


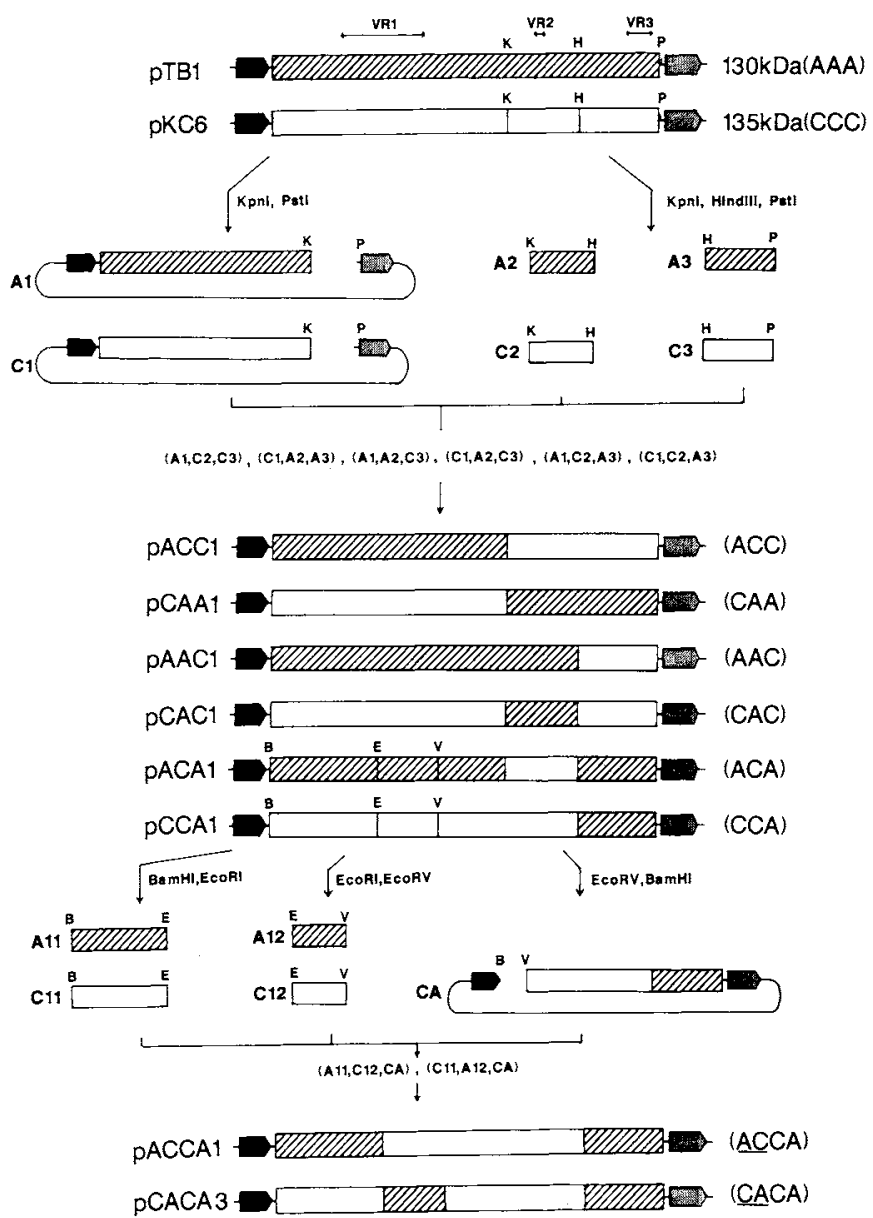

Fig. 1. Construction of Expression Plasmids for Chimeric IPs.

The expression plasmids pTB 1 and pKC6 for the $130-\mathrm{kDa}$ and $135-\mathrm{kDa}$ IP genes were divided into three fragments by digestion at KpnI, HindIII, and $P_{s t} \mathrm{I}$ sites. The three fragments of pTB 1 were exchanged with the corresponding fragments of $\mathrm{pKC} 6$, and then religated to yield six chimeric expression plasmids $\mathrm{pACC} 1$, pCAA1, pAAC1, pCAC1, pACA1, and pCCA1. The expression plasmids pACCA1 and pCACA3 were constructed by exchanging the $B a m \mathrm{HI}-E c o$ RI fragment and $E c o$ RI-EcoRV fragment of the plasmid pCCAI with the corresponding fragments of the plasmid pACAl. Hatched and open boxed regions indicate the coding regions for the $130-\mathrm{kDa}$ and $135-\mathrm{kDa}$ IPs, respectively. Black and dotted arrows show the tac promoter and $r m B$ transcription terminator, respectively. Thin lines represent the vector plasmid pKK223-4. Restriction enzyme sites are shown as follows: B, BamHI; E, EcoRI; H, HindIII; K, KpnI; P, Pst I; V, EcoRV.

ic IPs. Six chimeric IP genes were constructed by exchanging three fragments and two subfragments prepared by cleavage at homologous sites of both $130-\mathrm{kDa}$ IP and $135-\mathrm{kDa}$ IP genes. Both pTB1 and pKC6 were cleaved at KpnI, HindIII, and PstI sites, to divide the coding regions into three fragments. The resulting fragments, Pst I-KpnI, KpnI-HindIII, and HindIII-Pst I, included the variable regions VR1, VR2, and VR3, respectively. Thus, the $130-\mathrm{kDa}$ and $135-\mathrm{kDa}$ IPs divided into the three segments were called AAA and $\mathrm{CCC}$, respectively. The three prepared DNA fragments were religated with a change in assortment to yield six expression plasmids, $\mathrm{pACCl}$, pCAAl, pAACl, pCACl, pACAl, and pCCA1, for chimeric IPs called ACC, CAA, $\mathrm{AAC}, \mathrm{CAC}, \mathrm{ACA}$, and CCA, respectively. Both pACAl and pCCAl were cleaved at the EcoRI site to divide the amino-terminal $\mathrm{A}$ and 
$\mathrm{C}$ segments into two portions. The resulting $B a m \mathrm{HI}-E c o \mathrm{RI}$ and Eco RI-Eco RV fragments of the plasmid pCCAl were exchanged with the corresponding fragments of the plasmid pACAl to yield two expression plasmids, pACCA1 and pCACA3, for chimeric IPs called $\mathrm{ACCA}$ and $\mathrm{CACA}$, respectively. In the constructed expression plasmids, the chimeric IP genes were each inserted between the tac promoter and the $\operatorname{rrn} B$ terminator in the correct orientation.

\section{Production of chimeric IPS in E. coli}

E. coli JM103 cells were transformed with each of the constructed expression plasmids. The transformants were cultivated at $37^{\circ} \mathrm{C}$ for $15 \mathrm{hr}$ and then analyzed by SDS-PAGE. The intensive bands with molecular masses ranging from $130 \mathrm{kDa}$ to $135 \mathrm{kDa}$ as estimated from the constructed expression plasmids were found in the recombinant $E$. coli strains (Fig. $2 \mathrm{~A}$, lanes 2 to 11 ). No protein bands corresponding to molecular masses from $130 \mathrm{kDa}$

A

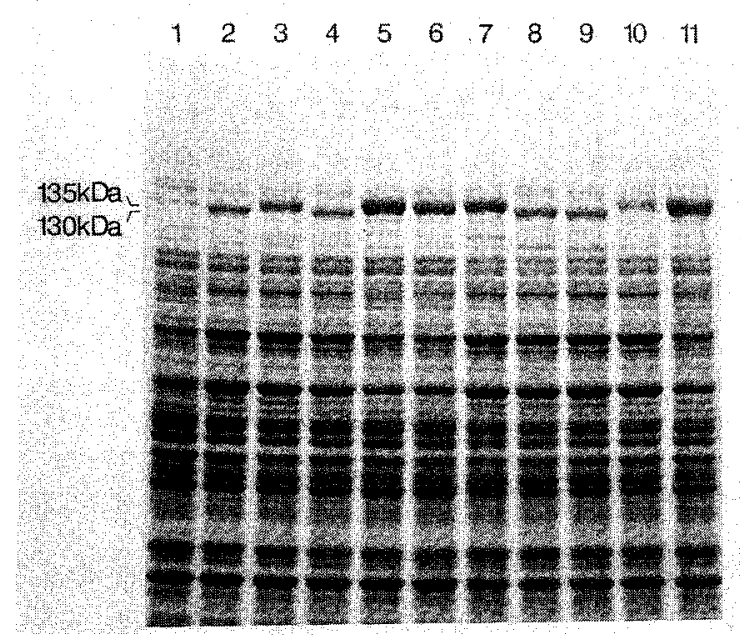

to $135 \mathrm{kDa}$ were found in the control cells (JM103/pKK223-4) (Fig. 2A, lane 1). The bands with molecular masses from $130 \mathrm{kDa}$ to $135 \mathrm{kDa}$ were reacted with anti-IP antibodies raised against the protein crystals consisting of the 130 and $135-\mathrm{kDa}$ IPs of the aizawai IPL7 strain (data not shown). Under optimal culture conditions, the chimeric IPs amounted to approximately $20-30 \%$ of the total cellular protein, as measured by densitometric scanning of the SDS-PAGE gels (data not shown). The molecular masses of the chimeric IPs, AAC, $\mathrm{CAA}$ and $\mathrm{CAC}$, which contained a 26 amino acid deletion, were estimated to be about $130 \mathrm{kDa}$ on the basis of the mobility on the SDS-PAGE gels. Similarly, the molecular masses of the other chimeric IPs such as ACA, ACC, CCA, ACCA, and CACA were approximately $135 \mathrm{kDa}$. Judging from intensity of the protein bands in Fig. 2A, the 135$\mathrm{kDa}$ IPs, CCC, ACA, ACC, CCA, and $\mathrm{CACA}$, were produced to slightly higher extents in the recombinant $E$. coli cells than the
B

$$
1234567899
$$

Fig. 2. Polyacrylamide Gel Analysis of Chimeric IPs Produced in Recombinant $E$. coli Cells

A. E. coli JM103 cells harboring each of the expression plasmids were cultivated at $37 \mathrm{C}$ for $15 \mathrm{hr}$, and cell extracts were analyzed by SDS-7.5\% PAGE. Proteins were stained with Coomassie brilliant blue. Lanes: 1 , JM103/pKK223-4; 2, JM103/pTB1; 3, JM103/pKC6; 4, JM103/pAAC1; 5, JM103/pACA1; 6, JM103/ pACCI; 7, JM103/pCCA1; 8, JM103/pCAA1; 9, JM103/pCACl; 10, JM103/pACCA1; 11, JM103/pCACA3. B. Inclusion bodies of the chimeric IPs were prepared from cultured recombinant $E$. coll cells, and $4.5-\mu \mathrm{g}$ samples of protein preparations were analyzed by SDS-7.5\% PAGE. Proteins were stained with Coomassie brilliant blue. Lanes: 1, AAA; 2, CCC; 3, AAC; 4, ACA; 5, ACC; 6, CCA; 7, CAA; 8, CAC; 9, ACCA; 10, CACA. 
130-kDa IPs such as AAA, AAC, CAA, and CAC, and the 135-kDa IP ACCA.

When observed under a phase contrast microscope, the cultured E. coli cells carrying each of the expression plasmids contained inclusion bodies at stationary phase. The inclusion bodies were isolated from the cultured recombinant $E$. coli cells by the combination of sonication and centrifugation, and then the proteins in the inclusion bodies were analyzed by SDS-PAGE (Fig. 2B). Densitometric scanning showed that the inclusion body preparations contained the corresponding chimeric IPs with approximately $80 \%$ purity (data not shown).

\section{Solubility in an alkaline buffer of inclusion bodies}

Solubilization under non-reducing alkaline conditions of IP crystals seems to be the first step for the activation processes in insect guts. Therefore, the inclusion bodies prepared from the cultured recombinant $E$. coli cells were examined for solubility in $25 \mathrm{~mm} \mathrm{Na} \mathrm{CO}_{3}-\mathrm{HCl}$ buffer ( $\mathrm{pH} 9.65$ ), the $\mathrm{pH}$ of which was adjusted to that of the gut-juice fraction prepared from
S. litura larvae. After incubation of the inclusion bodies in the alkaline buffer, the reaction mixtures were centrifuged to separate soluble fractions from insoluble precipitates. Both fractions were analyzed by SDS-PAGE. As shown in Fig. 3, the inclusion bodies of ACC and $\mathrm{CCC}$ were solubilized to the degrees of 85 $90 \%$. On the other hand, the inclusion bodies of ACA and CCA were rather insoluble under the same conditions and were recovered to degrees of less than $5 \%$ in the soluble fractions. These results indicated that the inclusion bodies of the chimeric IPs with the structure of XXC (X implies $\mathrm{A}$ or $\mathrm{C}$ ) were soluble, but those of the chimeric IPs with the structure of $\mathrm{XCA}$ were rather insoluble in the alkaline buffer. The inclusion bodies of AAA, CAA, $\mathrm{AAC}$, and $\mathrm{CAC}$ containing the central $\mathrm{A}$ segment showed intermediate solubility in the alkaline buffer. Both AAA and CAA were solubilized to extents of $50-55 \%$, but AAC and CAC had slightly less solubility than AAA and CAA. These results suggested that the combination of the central $\mathrm{C}$ segment and the carboxyl-terminal C or A segment is important for determination of solubility of the inclusion

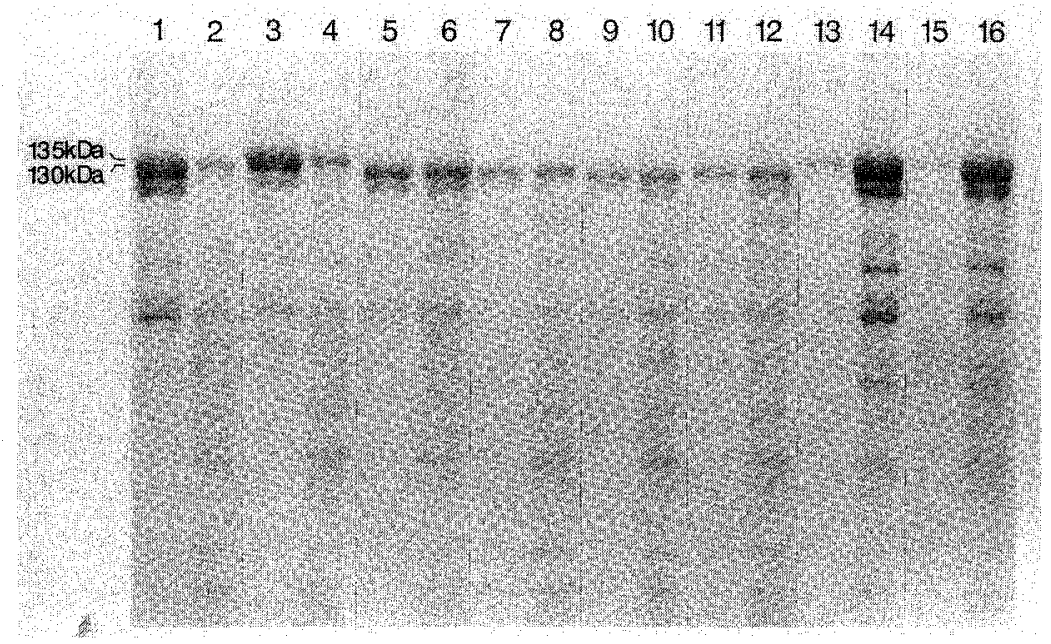

Fig. 3. Solubilization in an Alkaline Solution of Inclusion Bodies of Chimeric IPs.

Inclusion bodies of chimeric IPs were prepared from cultured recombinant $E$. coli cells as described in Materials and Methods, and incubated in $25 \mathrm{mM} \mathrm{Na}_{2} \mathrm{CO}_{3}-\mathrm{HCl}$ buffer ( $\mathrm{pH} \mathrm{9.65)} \mathrm{at} 30^{\circ} \mathrm{C}$ for $60 \mathrm{~min}$. Both supernatant and pellet fractions were prepared by centrifugation and then analyzed by SDS-10\% PAGE. Lanes: 1 and 2, ACC; 3 and 4, CCC; 5 and 6, AAA; 7 and 8, CAA; 9 and 10, AAC; 11 and 12, CAC; 13 and 14, ACA; 15 and 16, CCA; lanes 1,3,5,7,9,11,13, and 15, for the supernatants; lanes 2, 4, 6, 8, 10,12, 14, and 16, for the pellets. 


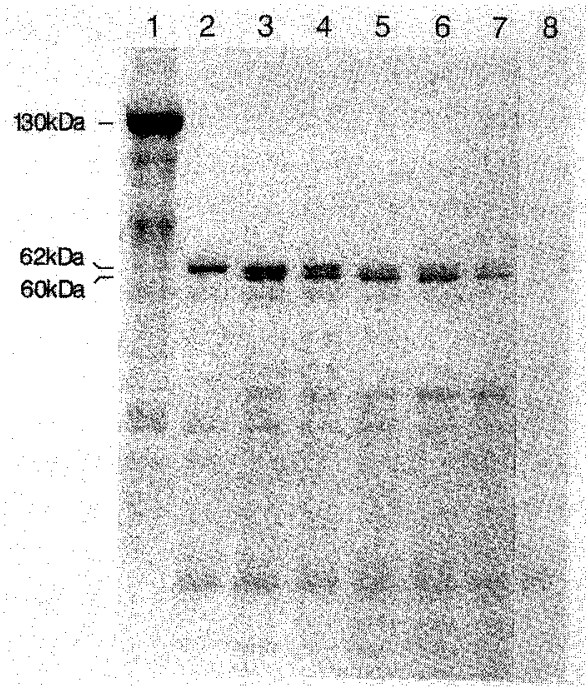

Fig. 4. Processing of the $130-k D a$ IP in the Gut Juice of Spodoptera litura Larvae.

The $130-\mathrm{kDa}$ IP (AAA) produced in the E. coli JM 103/ pTB1 cells was purified and incubated with the gut juice of $S$. litura larvae as described in Materials and Methods. The reaction mixtures corresponding to $8.5 \mu \mathrm{g}$ of the AAA were analyzed by SDS-10\% PAGE. Lanes: 1, AAA; 2, 3, $4,5,6$, and 7 , AAA incubated with the gut juice for 2,30 , $60,120,240$, and $480 \mathrm{~min}$, respectively; 8 , the gut-juice fraction. bodies of the chimeric IPs in the alkaline buffer.

Processing of chimeric IPs in a larval gut juice The inclusion bodies of the $130-\mathrm{kDa}$ IP (AAA) produced in the JM103/pTB1 cells were incubated with the gut-juice fraction prepared from $S$. litura larvae in the alkaline buffer ( $\mathrm{pH}$ 9.65). As shown in Fig. 4, the parental AAA was rapidly digested to yield a major polypeptide with the molecular mass of $62 \mathrm{kDa}$ after $2 \mathrm{~min}$ of incubation. The polypeptide was then converted to a $60-\mathrm{kDa}$ fragment during further incubation. The $60-\mathrm{kDa}$ fragment was maintained during $8 \mathrm{hr}$ incubation. The $60-\mathrm{kDa}$ fragment was purified and confirmed to be as toxic as the parental AAA against $S$. litura larvae. In addition, the amino-terminal five amino acid residues of the purified $60-\mathrm{kDa}$ fragment were identical to the sequence from amino acid residue 29 to 33 of the parental AAA (data not shown).

The chimeric IPs produced in the recombinant $E$. coli cells were also incubated with

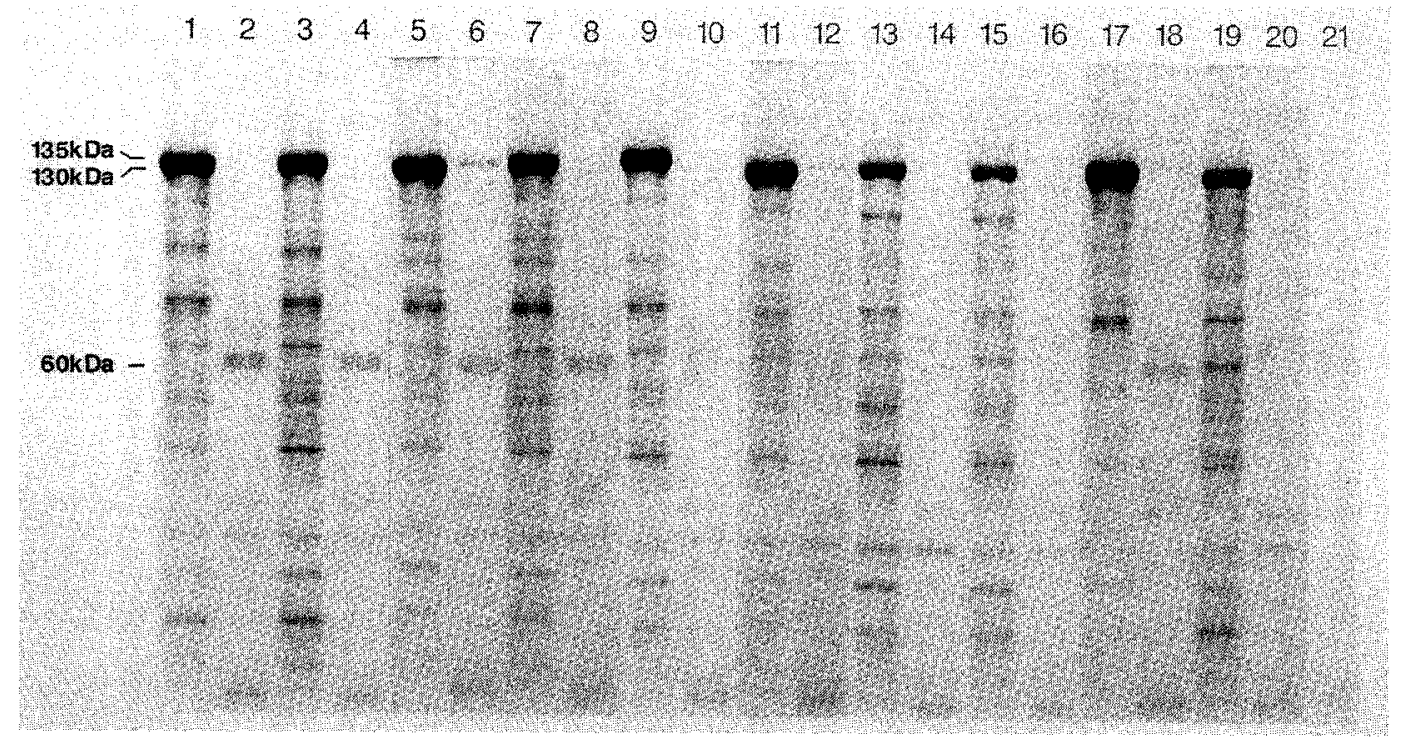

Fig. 5. Proteolytic Digestion of Chimeric IPs.

Chimeric IP preparations and reaction conditions were the same as described in the footnotes of Fig. 4. Chimeric IP preparations were each incubated with the gut juice for $45 \mathrm{~min}$, and then analyzed by SDS-10\% PAGE. Lanes: 1 and 2, AAA; 3 and 4, AAC; 5 and 6, ACA; 7 and $8, \mathrm{ACC} ; 9$ and 10, CCC; 11 and 12, CCA; 13 and 14, CAA; 15 and 16, CAC; 17 and 18, CACA; 19 and 20, ACCA; 21, the gut-juice fraction. 1, 3, 5, 7, 9, 11, $13,15,17$, and 19 , incubated without the gut juice; $2,4,6,8,10,12,14,16,18$, and 20 , incubated with the gut juice. 
the gut juice in the alkaline buffer. Samples of the reaction mixtures were analyzed by SDSPAGE before and after incubation. As shown in Fig. 5, the chimeric AAC, ACA, and ACC (AXX) containing the amino-terminal A segment yielded nearly the same amount of 60 $\mathrm{kDa}$ to $62-\mathrm{kDa}$ fragments as those from the parental AAA (Fig. 5, lanes 2, 4, 6, and 8). On the other hand, the $60-\mathrm{kDa}$ to $62-\mathrm{kDa}$ fragments were hardly found with $\mathrm{CCC}, \mathrm{CCA}$, $\mathrm{CAA}$, and $\mathrm{CAC},(\mathrm{CXX})$, which contained the amino-terminal $\mathrm{C}$ segment (Fig. 5, lanes 10 , 12,14 , and 16). The chimeric CACA produced $60-\mathrm{kDa}$ to $62-\mathrm{kDa}$ fragments to a extent similar to that of the parental AAA, while the other chimeric ACCA showed faint bands (Fig. 5, lanes 18 and 20). Thus, the chimeric IPs containing the carboxy-terminal half of the amino-terminal A segment yielded nearly the same amount of the $60-\mathrm{kDa}$ to $62-\mathrm{kDa}$ fragments as those from the parental AAA. Therefore, this segment seemed to be closely related to the formation of the $60-\mathrm{kDa}$ to $62-$ $\mathrm{kDa}$ fragments from the IPs.

\section{Insecticidal activity of chimeric IPS}

The insecticidal activity of the chimeric IPs prepared from the cultured recombinant $E$. coli cells was tested against larvae of $S$. litura and $P$. xylostella. Table I shows the averaged values of several repeated experiments. The chimeric IPs containing the amino-terminal A segment (AXX) showed nearly the same insecticidal activities as those of the parental AAA against both $S$. litura and $P$. xylostella, although $\mathrm{AAC}$ was slightly less active against S. litura than the other three IPs (AAA, ACC, and ACA). The chimeric IPs with the aminoterminal $\mathrm{C}$ segment (CXX) showed the insecticidal activity against $P . x y$ lostella similar to that of the parental $\mathrm{CCC}$, while CAA and CAC were less active against $S$. litura than the others (CCC and CCA). The chimeric CACA and ACCA had much lower activities against S. litura than ACA and CCA. On the other hand, both CACA and ACCA showed nearly the same activities against $P$. xylostella as those of ACA and CCA, respectively. These results indicated that the amino-terminal $A$ segment is responsible for the insecticidal activity against both $S$. litura and $P$. xylostella, and the carboxy-terminal half of the aminoterminal A segment is important for the insecticidal activity against $P$. xylostella. The

Table I. Insecticidal Activities of Chimeric IPs Produced in Recombinant E. coli Cells

\begin{tabular}{|c|c|c|c|c|}
\hline \multirow{4}{*}{ Chimeric $\mathrm{IP}^{a}$} & \multicolumn{4}{|c|}{$\%$ Mortality } \\
\hline & \multicolumn{2}{|c|}{ Spodoptera litura ${ }^{b}$} & \multicolumn{2}{|c|}{ Plutella xylostella } \\
\hline & \multicolumn{2}{|c|}{ Dose } & \multicolumn{2}{|c|}{ Dose } \\
\hline & $0.3 \mathrm{mg} / \mathrm{ml}$ & $1 \mathrm{mg} / \mathrm{ml}$ & $0.2 \mu \mathrm{g} / \mathrm{ml}$ & $2 \mu \mathrm{g} / \mathrm{ml}$ \\
\hline $\mathrm{AAA}(130 \mathrm{kDa})$ & 60 & 90 & 30 & 100 \\
\hline $\mathrm{ACC}$ & 50 & 100 & 40 & 100 \\
\hline $\mathrm{AAC}$ & 10 & 60 & 10 & 80 \\
\hline $\mathrm{ACA}$ & 50 & 100 & 30 & 70 \\
\hline $\mathrm{CCC}(135 \mathrm{kDa})$ & 10 & 90 & 10 & 20 \\
\hline $\mathrm{CCA}$ & 0 & 90 & 20 & 20 \\
\hline CAA & 0 & 30 & 20 & 30 \\
\hline $\mathrm{CAC}$ & 0 & 0 & 10 & 20 \\
\hline CACA & 0 & 10 & 30 & 80 \\
\hline$\overline{\mathrm{ACCA}}$ & 0 & 0 & 20 & 20 \\
\hline
\end{tabular}

a Each of chimeric IPs produced in recombinant $E$. coli cells was partially purified as described in Materials and Methods.

$b$ Counted 3 days after treatment of 10 larvae per sample.

c Counted 4 days after treatment of 10 larvae per sample. 
amino-terminal segment covered the entire 60 $\mathrm{kDa}$ active fragment.

\section{Discussion}

Figure 6 is a comparison of the amino acid sequences deduced from the 130-kDa and 135 $\mathrm{kDa}$ IP genes of the aizawai strain. The overall similarity in the total amino acid sequences was $90.2 \%$. Amino acid differences, deletions, and insertions occurred mainly in the three variable regions, VR1, VR2, and VR3. VR1 was from amino acid residues 206 to 455 of the $135-\mathrm{kDa}$ IP, which contained 68 amino acid differences in the 250 amino acid residues. VR2 from amino acid residues 788 to 819 contained a 26 amino acid insert and one amino acid difference. VR3 from amino acid residues 1,061 to 1,137 contained a 4 amino acid deletion and 15 amino acid differences in the 77 amino acid residues. The 130- and 135$\mathrm{kDa}$ IPs contained 12 and 17 cysteine residues, respectively. Particularly, the 26 amino acid insert in the VR2 region derived from the 135 $\mathrm{kDa}$ IP contained 4 cysteine residues.

Eight chimeric IP genes were constructed by exchanging three fragments and two subfragments prepared by cleavage at the homologous sites of the 130-kDa IP (AAA) gene with the corresponding fragments of the $135-\mathrm{kDa}$ IP (CCC) gene, and were expressed in $E$. coli cells. Although the production levels of most of the chimeric IPs were nearly the same as those of the parental AAA and CCC, the chimeric IPS containing the central $\mathrm{C}$ segment $(\mathrm{XCX}$ ) were produced at slightly higher levels than the chimeric IPs containing the central A segment (XAX). Huber et al. ${ }^{20)}$ reported that the cysteine residues in the IPs of subsp. kurstaki HD1 are involved in crystal formation. Thus, this may suggest that the additional four cysteine residues $(794,800,812$, and 814$)$ located in the 26 amino acid insert in the VR2 region of the central $\mathrm{C}$ segment are important for stability in the recombinant $E$. coli cells of the chimeric IPs, probably due to formation of intrachain disulfide bonds. The chimeric IPs with different combinations of the central and carboxy-terminal segments showed differences in the solubility in the alkaline buffer under non-reducing conditions. The chimeric IPs with the structure of XCC were soluble and the IPs with XCA were rather insoluble. Couche et al. $^{21)}$ reported that solubilization of the crystal proteins of $B$. thuringiensis subsp. israelensis required disulfide cleavage, either in the presence of a reducing agent such as mercaptoethanol or at $\mathrm{pH} 11.75$ or greater. It is, there-

\section{0kDa}
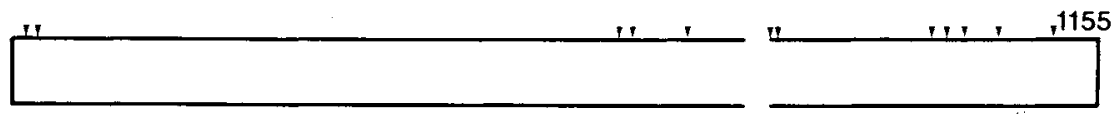

$135 \mathrm{kDa}$

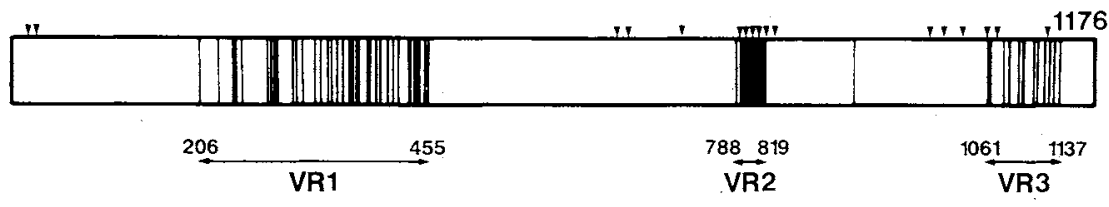

$\mathbf{N}$

0

200

400

600

800

1000

Fig. 6. Comparison of the Amino Acid Sequences of Both 130-kDa and 135-kDa IPs of B. thuringiensis subsp. aizawai.

Boxes show the entire primary structures of both 130 and $135-\mathrm{kDa}$ IPs, and vertical lines in the $135-\mathrm{kDa}$ IP indicate the amino acid residues which are different from those of the $130-\mathrm{kDa}$ IP sequence. Gaps show deleted regions. Arrowheads indicate location of cysteine residues. VR1, VR2, and VR3 indicate the variable regions found in the amino acid sequences between the $130-\mathrm{kDa}$ and $135-\mathrm{kDa}$ IPs. Numerals indicate amino acid residues of the 135-kDa IP. N. Amino-terminus; C, carboxy-terminus. 
fore, presumable that the solubility of the chimeric IPs is related to combination of the cysteine residues located in the VR2 and VR3 regions.

Digestion of the parental AAA with the gut juice prepared from $S$. litura larvae produced a $60-\mathrm{kDa}$ active fragment. Nagamatsu et al. ${ }^{191}$ isolated a trypsin-resistant toxic peptide with the molecular mass of $58 \mathrm{kDa}$ from the IP of $B$ thuringiensis subsp. dendrolimus. Höfte et al. ${ }^{9}$ also purified a polypeptide with the molecular mass of $60 \mathrm{kDa}$ from the IP of $B$. thuringiensis subsp. berliner 1715. The amino-terminal five amino acid residues of the $60-\mathrm{kDa}$ fragment derived from the parental AAA was identical to those of the reported trypsin-resistant peptides. ${ }^{919)}$ The comparison of digestion profiles of the chimeric IPs with the gut juice of $S$. litura larvae suggested that the amino-terminal A segment, particularly, the carboxy-terminal half of VR1 ranging from positions 333 to 456 is important for formation of the $60-\mathrm{kDa}$ active fragment in the gut juice.

Comparison of the insecticidal activities of the chimeric IPs against larvae of S. litura and $P$. xylostella suggested that VR1 of the aminoterminal A segment is responsible for the activity. In particular, the carboxy-terminal half of VRI was important for the activity against $P$. xylostella, although the region was not sufficient for the activity against $S$. litura. Also, the chimeric IPs with different combinations of VR1 (ACA, CCA, CACA, ACCA) had different insecticidal specificities. So, VR1 appeared to be important in establishing the insecticidal specificity of the IPs. In addition, the chimeric IPs with different combinations of VR2 and VR3 derived from the parental AAA and CCC were different to some extent in the insecticidal activity against $S$. litura. Thus, VR2 and VR3, which were outside of the $60-\mathrm{kDa}$ active fragment, may be related to activation processes in the gut juice.

Recently, Ge et al. $^{22)}$ reported the construction of chimeric IPs between $B$. thuringiensis subsp. kurstaki HD-1 IP and B. thuringiensis subsp. kurstaki HD-244 IP. Comparison of the insecticidal activity against
Bombyx mori of the chimeric IPs produced in $E$. coli cells suggested that the $B$. mori specificity domain of the HD-1 IP is in the aminoterminal portion of the hypervariable region (positions 332 to 450 ). This observation agreed well with our results showing that VR1, in the $60-\mathrm{kDa}$ active fragment, is important for insecticidal activity of the chimeric IPS.

Elucidation of the structure-function relationships related to VR1, VR2, and VR3 appears to be useful for design of engineered IPS with improved insecticidal activity, insecticidal spectra, and stability.

\section{References}

1) H. T. Dulmage, "Microbial Control of Pests and Plant Diseases 1970 1980," ed. by H. D. Burges, Academic Press, London, 1981, p. 193.

2) M. M. Lecadet and D. Martouret, J. Invertebr. Pathol., 9, 322 (1967).

3) A. Klier, F. Fargette, J. Ribier and G. Rapoport, EMBO J, 1, 791 (1982).

4) H. E. Schnepf, H. C. Wong and H. R. Whiteley, $J$. Biol. Chem., 260, 6264 (1985).

5) Y. Shibano, A. Yamagata, N. Nakamura, T. Iizuka, H. Sugisaki and M. Takanami, Gene, 34, 243 (1985).

6) M. J. Adang, M. J. Staver, T. A. Rocheleau, J Leighton, R. F. Barker and D. V. Thompson, Gene, 36. 289 (1985).

7) L. Thorne, F. Garduno, T. Thompson, D. Decker, M. Zounes, M. Wild, A. M. Walfield and T. J. Pollock, J. Bacteriol., 166, 801 (1986).

8) H. Wabiko, K. C. Raymond and L. A. Bulla, Jr., DNA, 5, 305 (1986).

9) H. Höfte, H. de Greve, J. Seurinck, S. Jansens, J Mahillon, C. Ampe, J. Vandekerckhove, $H$. Vanderbruggen, M. van Montagu, M. Zabeau and M. Vaeck, Eur. J. Biochem., 161, 273 (1986).

10) M. Geiser, S. Schweitzer and C. Grimm, Gene, 48 , 109 (1986)

11) S. Kondo, N. Tamura, A. Kunitate, M. Hattori, A. Akashi and I. Ohmori, Agric. Biol. Chem., 51, 455 (1987).

12) A. G. Shivakumar, G. J. Gundling, T. A. Benson, D. Casuto, M. F. Miller and B. B. Spear, J. Bacteriol., 166, 194 (1986).

13) S. Calogero, A. M. Albertini, C. Fogher, R. Marzari and A. Galizzi, Appl. Environ. Microbiol., 55, 446 (1989)

14) K. Oeda, K. Oshie, M. Shimizu, K. Nakamura, H. Yamamoto, I. Nakayama and H. Ohkawa, Gene, 53, 113 (1987).

15) M. Shimizu, K. Oshie, K. Nakamura, Y. Takada, K Oeda and H. Ohkawa, Agric. Biol. Chem., 52, 1565 
(1988).

16) H. C. Birnboim and J. Doly, Nucleic Acids Res., 7, 1513 (1979).

17) S. N. Cohen, A. C. Y. Chang and L. Hsu, Proc. Natl. Acad. Sci. U.S.A., 69, 2110 (1972).

18) U. K. Laemmli, Nature, 227, 680 (1970).

19) Y. Nagamatsu, Y. Itai, C. Hatanaka, G. Funatsu and K. Hayashi, Agric. Biol. Chem., 48, 611 (1984).

20) H. E. Huber, P. Lüthy, H. R. Ebersold and J, L. Cordier, Arch. Microbiol., 129, 14 (1981).

21) G. A. Couche, M. A. Pfannenstiel and K. W. Nickerson, J. Bacteriol., 169, 3281 (1987).

22) A. Z. Ge, N. I. Shivarova and D. H. Dean, Proc. Natl. Acad. Sci. U.S.A., 86, 4037 (1989). 